\title{
Investigation of Long-Term COVID-19 Patients' Quality of Life and Affecting Factors: Data from Single COVID-19 Follow-Up Center
}

Anıl Uçan ( $\nabla$ anil.ucan@saglik.gov.tr)

Eskisehir City Hospital

Şebnem Eker Güvenç

Eskisehir City Hospital

Fezan Şahin Mutlu

Eskişehir Osmangazi University

Fulya Bakılan

Eskisehir City Hospital

Yaşar Bildirici

Eskisehir City Hospital

\section{Research Article}

Keywords: COVID-19 Follow up Centre, SF-36, Quality of life

Posted Date: January 28th, 2022

DOI: https://doi.org/10.21203/rs.3.rs-1292045/v1

License: (9) This work is licensed under a Creative Commons Attribution 4.0 International License.

Read Full License 


\section{Abstract}

Background: The main challenge faced by many researchers is to predict and monitor the long-term outcome of patients with COVID-19. The purpose of this article is to explore the relationship between quality of life change and long-term COVID-19 patient's stats in COVID-19 Follow-up Centre.

Methods: This study was designed retrospectively with patients who admitted COVID-19 Follow-up Centre of between January and May 2021. Study sample consisted of 125 patients divided into two groups according to their admission date. $1^{\text {st }}$ admission indicates of first 3 months and $2^{\text {nd }}$ admission covers $3-6$ months after diagnosed with COVID-19. Patient values recorded retrospectively with a form which includes questions about the socio-demographic characteristics of individuals, comorbidities, and the assessment of the patient's health-related quality of life with the SF-36 scale.

Results: Comparison of baseline characteristics showed that cough and chest pain have been increased in second admission ( $p$ 0.001). Thirty-six item of short form Health Status Questionnaire-36 (SF-36) measured quality of life and there was a significant difference between first and second admission in all parameters. However, no significant differences were found in SF-36 change according to age. Only trace amounts of decreasing in General Health sub-group were detected in females compare to males $(p=0.004)$. In addition, comparing with the SF-36 subgroups in terms of treatment places, only a significant difference between the inpatient and I.C.U groups in General Health sub-group $(p=0.044)$.

Conclusions: In summary, these findings have significant implications for the understanding of long term COVID-19 patients with a multidisciplinary approach and necessity of follow-up centers for detection of the unpredictable results of the long-term COVID-19.

\section{Introduction}

The New Coronavirus (SARS-CoV-2) spread worldwide in 2019 by affecting the respiratory tract, like other members of the coronavirus family, and turned into a pandemic that affected the whole world as of 2020, and as of July 30,2021, 195 million confirmed cases worldwide were reached [1]. The prevalence and severity of the disease demanded post-discharge follow-up, and it was discovered that particularly persistent psychological and physical symptoms remained after discharge [2]. At the first stage of the COVID-19 outbreak in China, 53.8\% of participants experienced a moderate or severe psychological effect of the outbreak [3], and significant changes in health-related quality of life scales were observed in people who had the disease, leaving serious psychological and physiological effects in patients during follow-up at the end of the 1-month process [4]. Changes in quality of life were observed in patients with mental disorders after COVID-19. These changes have shown that all patients should be dynamically monitored in terms of mental stress, sleep, overall health and quality of life at admission and discharge that could make early predictions of possible long-term effects of COVID-19 [5]. Health-related quality of life (HRQoL) is an assessment that expresses the effect of disease and treatment on patients' function and overall life satisfaction [6]. In studies, it was observed that patients' HRQoL values could be evaluated 
using the 36-item short form Health Status Questionnaire-36 (SF-36) scale, emphasizing the ease of use of this scale $[7,8]$. It has been shown to be valid and acceptable in the healthy population, and safety studies have been conducted in different patient groups. The SF-36 questionnaire was used to assess the quality of life of patients with respiratory tract infections of the Middle East respiratory syndrome (MERS) and other coronavirus family such as SARS-CoV-1 $[9,10]$. However much less is known about how quality of life in COVID-19 patients follow-up changes. Recently, there has been renewed interest in evaluate COVID-19 patients with SF-36 [11, 12]. The long-term effects of COVID-19 has prompted the Ministry of Health to establish the COVID-19 Follow-up Centers. The Data received from Centers may provide an important opportunity to advance the understanding of long-term effects in COVID-19 patients.

In this study, it was aimed to determine the HRQoL change with SF-36 and predictive factors of patients evaluated in the COVID-19 Follow-up Centre in three groups; after home quarantine, discharge from inpatient services and intensive care units due to COVID-19.

\section{Methods}

\section{Study design and participants}

This study was conducted in a large tertiary care hospital in Eskişehir, Turkey with patients who were diagnosed with reverse transcription-polymerase chain reaction (RT-PCR) of nasopharyngeal swab and needed to be followed-up by COVID-19 Follow-up Centre of between January and May 2021. Patients were referred to the COVID-19 Follow-up Centre outpatient clinic with ongoing symptoms were analyzed retrospectively to determine potential changes in their baseline status and quality of life assessments. The inclusion criteria were being 18 years or older, having COVID-19 treatment (home quarantine/hospital/intensive care unit) according to a positive polymerase chain reaction (PCR) test in a nasopharyngeal + oropharyngeal swab or chest computed tomography (CT) and examined in COVID-19 Follow-up Centre outpatient clinic. Patients who had both negative PCR test and chest CT and also acute COVID-19 patients (patients whose symptoms had started less than one month) were excluded. In addition, patients who did not come for control examination after the first application to the COVID-19 Follow-up Centre were excluded from the study. Participants read and accepted the information consent form before answering the questionnaire.

\section{Measurements}

Patients followed-up by COVID-19 Follow-up Centre were examined in two groups according to their admission to the Centre for control at the $1^{\text {st }}$ three months and $2^{\text {nd }}$ three months after diagnosed. All patients were evaluated with a form which includes questions about the socio-demographic characteristics of individuals, comorbidities, and the assessment of the patient's health-related quality of life with the SF-36 scale. 
A detailed anamnesis was recorded about age, gender, body mass index, education, martial status, working status, co-morbidities (diabetes mellitus, hypertension, chronic obstructive pulmonary disease, cardiac disease, thyroid abnormalities, renal disease, cancer, etc.), smoking, place of treatment (home quarantine, hospital, intensive care unit), duration of treatment in hospital.

Ongoing symptoms after COVID-19 disease were noted in the 1st and 2nd admissions to COVID-19 Follow-up Centre. Among the controls, a multidisciplinary patient follow-up was performed by referring the patients to the relevant clinics with predetermined referral criteria for their symptoms.

\section{Quality of life assessment}

SF-36 (short form 36, short form 36 ) is a general health screening questionnaire designed in the USA and been translated in almost 50 countries to assess quality of life [13]. SF-36 short form consist of; physical functioning (PF), physical role limitation (RP), bodily pain (BP), general health (GH), vitality (VT), social functioning (SF), emotional role limitation (RE), and mental health $(\mathrm{MH})$ status. It measures health on eight scales and each scale ranges from 0 (poor health) to 100 (perfect health) with higher scores show better quality of life [14].

\section{Statistical Analysis}

The distribution of each continuous variable was tested for normality using the Shapiro-Wilk test and is expressed as mean standard deviation (SD) and median value [interquartile range (IQR)]. The categorical variables are expressed in frequencies. Normally distributed variables were performed using paired t-test or independent $t$ test. Non-normally distributed variables were performed using the Mann Whitney $U$ and Wilcoxon Signed Ranks Test. Mc Nemar Chi-square test was used to compare categorical variables. The Spearman correlation coefficient was used as the correlation analysis. A p-value $<0.05$ was considered significant. All analyses were performed using the SPSS version 21.0 software (SPSS Inc., Chicago, IL, USA).

\section{Results}

A total of 151 patients were included in this study. 21 patients who did not admit to COVID-19 Follow-up Center for the second time excluded. Also, 5 individuals were excluded from the study on the basis of could not cooperate with the questionnaire. The files of 125 COVID-19 patients ( 68 females, 57 males) (mean age $55 \pm 11.6$ ) were recorded and divided two groups according to $1^{\text {st }}$ admission and $2^{\text {nd }}$ admission after quarantine or hospital discharge. Table 1. illustrates some of the main characteristics of the patients.

Table 1. Baseline characteristics of patients 


\begin{tabular}{|c|c|}
\hline & $\begin{array}{l}\text { Frequencies } \\
\text { n (\%) }\end{array}$ \\
\hline Age (years) & $55.0 \pm 11.6$ \\
\hline Gender (female/male) n \% & $68(54 \%) / 57(46 \%)$ \\
\hline \multicolumn{2}{|l|}{ Chronic diseases } \\
\hline Diabetes & $21(\% 16.8)$ \\
\hline Hipertansion & $37(\% 29.6)$ \\
\hline COPD & $4(\% 3.2)$ \\
\hline Guatr & $9(\% 7.2)$ \\
\hline Cardiac diseases & $9(\% 7.2)$ \\
\hline Kidney disease & $1(\% 0.8)$ \\
\hline Cancer & $3(\% 2.4)$ \\
\hline \multicolumn{2}{|l|}{ Smoking } \\
\hline Yes & $10(\% 8)$ \\
\hline No & $115(\% 92)$ \\
\hline \multicolumn{2}{|l|}{ Working } \\
\hline Yes & $37(\% 29.6)$ \\
\hline No & $79(\% 63.2)$ \\
\hline Retired & $9(\% 7.2)$ \\
\hline \multicolumn{2}{|l|}{ Education } \\
\hline High school lower & $48(\% 38.4)$ \\
\hline High school and University & $18(\% 14.4)$ \\
\hline PhD and Doctorate & $59(\% 47.2)$ \\
\hline \multicolumn{2}{|l|}{ Married / single } \\
\hline Married & $106(\% 84.8)$ \\
\hline Single & $14(\% 11.2)$ \\
\hline Widow & $1(\% 0.8)$ \\
\hline Divorced & $4(\% 3.2)$ \\
\hline \multicolumn{2}{|l|}{ Treatment place } \\
\hline Home quarantine & $59(\% 47.2)$ \\
\hline
\end{tabular}


Inpatient services

Intensive care unit

Treatment duration in inpatient services (days) Mean \pm SD

Treatment duration in intensive care unit (days) Mean \pm SD
$46(\% 36.8)$

$20(\% 16)$

$5.1 \pm 6.0$

$3.5 \pm 8.5$

(COPD:Chronic Obstructive Lung Disease)

In all 125 patients who were admitted to COVID-19 Follow-up Center, the rate of dyspnea $71 \%$, cough $32 \%$, chest pain $21 \%$. Comparison of baseline characteristics showed that cough and chest pain have been increased in second admission $(p<0.001)$ (Table 2$)$.

Table 2. Comparison of symptoms and Short-Form 36 scores between first and second admission to COVID-19 Follow-up Center

$$
1^{\text {st }} \text { Admission } \quad 2^{\text {nd }} \text { Admission } \quad P
$$

\section{Symptoms n (\%)}

\begin{tabular}{|llll|}
\hline Cough & $63(\% 50.4)$ & $85(\% 68)$ & $<0.001$ \\
\hline Dyspnea & $22(\% 17.6)$ & $28(\% 22.4)$ & 0.180 \\
\hline Chest Pain & $29(\% 23.2)$ & $49(\% 39.2)$ & $<0.001$ \\
\hline SF-36 subgroups Median $(25-75 \%)$ & & \\
\hline Physical function & $80(60-95)$ & $70(50-90)$ & 0.001 \\
\hline Physical role & $100(25-100)$ & $50(0-100)$ & 0.001 \\
\hline Emotional role & $66.7(0-100)$ & $66.6(0-100)$ & 0.026 \\
\hline Bodily pain & $77.5(66.2-100)$ & $67.5(55-90)$ & $<0.001$ \\
\hline Energy & $55(45-68.7)$ & $50(35-60)$ & 0.007 \\
\hline Mental health* & $62.51 \pm 16.27$ & $60.25 \pm 17.51$ & 0.031 \\
\hline General health & $55(44.5-70)$ & $50(27.5-65)$ & $<0.001$ \\
\hline Social function & $62.5(50-87.5)$ & $50(37.5-75)$ & $<0.001$ \\
\hline
\end{tabular}

*mean \pm SD

Further statistical tests revealed in Table 2in terms of comparison with SF-36 Form sub-groups between $1^{\text {st }}$ Admission and $2^{\text {nd }}$ admission that the difference was significant in; Physical function, Physical 
role, Emotional role, Bodily pain, Energy, Mental health, General health, Social function subsequently $(p=0.001,0.001,0.026<0.001,0.007,0.031,<0.001,<0.001)$.

To compare the difference between gender and SF-36 parameters shown in Table 3 that the quality of life decreased significantly in female patients in the General Health component sum score of the SF-36 $(p=0.004)$.

Table 3. Comparison of SF-36 parameters change between first and second admission to COVID-19 Follow-up Center according to gender

\begin{tabular}{|llll|}
\hline & $\begin{array}{l}\text { Kadın }(\mathrm{n}=68) \\
\text { Median (25-75\%) }\end{array}$ & $\begin{array}{l}\text { Erkek }(\mathrm{n}=57) \\
\text { Median }(25-75 \%)\end{array}$ & $\mathrm{P}$ \\
\hline SF-36 subgroups & & & \\
Physical function & $-5(-20-5)$ & $-5(-15-5)$ & 0.830 \\
\cline { 2 - 4 } Physical role & $0(-25-0)$ & $0(-25-0)$ & 0.757 \\
Emotional role & $0(-33.3-0)$ & $0(-33.3-0)$ & 0.641 \\
Bodily pain & $-10(-22.5-0)$ & $-10(-22.5-0)$ & 0.612 \\
*Energy & $-3.44 \pm 17.07$ & $-3.77 \pm 18.48$ & 0.915 \\
*Mental health & $-3.08 \pm 12.13$ & $-1.2 \pm 12.46$ & 0.370 \\
General health & $-10(-20-3.7)$ & $0(-12.5-10)$ & 0.004 \\
Social function & $-6.2(-25-0)$ & $-12.5(-25-0)$ & 0.824 \\
\hline Weight & $0(0-0)$ & $0(-2-0)$ & 0.150 \\
\hline Age & $55(45.2-59.7)$ & $56(47.5-64.5)$ & 0.179 \\
\hline
\end{tabular}

\section{*mean \pm SD}

As the results of the statistical analysis are shown in Table 4, comparison of SF-36 change according to age groups showed that, there were found no statistically difference in SF-36 change according to being geriatric or adult.

Table 4. Comparison of SF-36 change between first and second admission to COVID-19 Follow-up Center according to age groups 


\begin{tabular}{|llll|}
\hline & $\begin{array}{l}\text { Adult population } \\
(\text { Age<65) }(n=98)\end{array}$ & $\begin{array}{l}\text { Geriatric population } \\
(\text { Age } \geq 65)(n=27)\end{array}$ & \\
& Median $(25-75 \%)$ & Median $(25-75 \%)$ & \\
\hline SF-36 subgroups & & & \\
\hline Physical function & $-5(-20-5)$ & $-5(-15-5)$ & 0.650 \\
\hline Physical role & $0(-25-0)$ & $0(-25-0)$ & 0.493 \\
\hline Emotional role & $0(-33-0)$ & $0(-33-0)$ & 0.955 \\
\hline Bodily pain & $-22.5(-10-0)$ & $-10(-22.5-0)$ & 0.684 \\
\hline Energy & $-5(-15-5.2)$ & $-5(-15-5)$ & 0.793 \\
\hline Mental health & $-2(-12-8)$ & $-4(-12-4)$ & 0.523 \\
\hline General health & $-5(-20-5)$ & $-5(-15-5)$ & 0.826 \\
\hline Social function & $-12.5(-25-0)$ & $0(-12.5-0)$ & 0.682 \\
\hline
\end{tabular}

In terms of the treatment areas of the patients were compared with the SF-36 subgroups, There was found only a significant difference between the inpatient and I.C.U groups in General Health (Table 5).

Table 5. Comparison of SF-36 change between first and second admission to COVID-19 Follow-up Center according to treatment places 


\begin{tabular}{|lllll|}
\hline Treatment Place & $\begin{array}{l}\text { Home Quarantine } \\
(\mathrm{n}=59) \\
\text { Median }(25-75 \%)\end{array}$ & $\begin{array}{l}\text { Inpatient Clinic } \\
(\mathrm{n}=46)\end{array}$ & $\begin{array}{l}\text { Intensive Care Unit } \\
(\mathrm{n}=20)\end{array}$ & P values \\
\hline SF-36 subgroups & & & & \\
Physical function & $-5(-10-5)$ & $0(-15-10)$ & $0(-45-20)$ & Ns \\
\hline Physical role & $0(-25-0)$ & $0(-25-0)$ & $0(-25-0)$ & Ns \\
\hline Emotional role & $0(-33.3-0)$ & $0(-29.1-0)$ & $0(-33.3-0)$ & Ns \\
\hline Bodily pain & $-10(-22.5-0)$ & $-10(-22.5-0)$ & $-13.7(-22.5-0)$ & Ns \\
\hline Energy & $0(-10-5)$ & $-5(-15-0)$ & $-15(-20-10)$ & Ns \\
\hline Mental health & $-4(-12-4)$ & $0(-12-4)$ & $2(-10-12)$ & Ns \\
\hline General health & $-5.0(-15.0-5.0)$ & $-5.0(-22.5-5.0)$ & $5.0(-5.0-10.0)$ & $0.044^{\mathrm{a}}$ \\
\hline Social function & $0(-25-0)$ & $0(-25-0)$ & $0(-21.8-12.5)$ & Ns \\
\hline
\end{tabular}

a the comparison of patients in Group 2 vs. Group 3. NS: non-significant

\section{Discussion}

The first question in this study sought to evaluate the changes of life quality over time and discovering variables that effects in post COVID-19 patients. Recent trends in COVID-19 have led to a proliferation of research on post-COVID-19 effects [15-17]. The importance and originality of this study are that it explores quality of life changes after COVID-19.

The most striking result to emerge from our study is that, all quality of life parameters evaluated by SF-36 were decreased in post acute 1st and 2nd admission to COVID-19 Follow-up Centre. Our study includes patients who had COVID-19 disease of different severity and were followed up at home or in the hospital as suggested by guidelines published by the Turkish Ministry of Health's Scientific Committee [18]. However, much of the current literature on outcomes and quality of life changes had focused on critical illness such as ARDS and sepsis [19-23].

In reviewing the literature, a data was found on the quality of life was impaired in \%44.1 of discharged patients according to EuroQoL visual analogue scale [24]. A study was conducted in China compared COVID-19 patients and normal population with SF-36 parameters that shows that patients had higher body pain and vitality scores, but lower physiological function, social function, and role-physical scores [25]. In our study, the general health parameter of patients hospitalized in the intensive care unit increased in the 2 admission. It is encouraging to compare this figure with that found by Wong (2020) who found that a third of patients with COVID-19 reporting at least moderate impairment in major 
dimensions of quality of life 3 months after symptom onset [26]. A Dutch study reported that quality of life was evaluated six weeks after COVID-19 pneumonia, and reported to be lower than Dutch population [27].

The next section of our study was concerned with identifying connections between age and treatment places. Comparing the COVID-19 treatment areas and the ages of the patients, it was seen that the patients in the hospital and intensive care unit were older than the patients treated at home. Contrary to expectations, our study did not find a significant difference in age groups (adult or elder) with SF-36 subgroups.

In the current study, comparing gender with SF-36 subgroups showed that the only significant difference in General Health worse in Female patients. A research showed that female sex was a predictor of mental component summary lower than 50 in SF-36 and suggesting that female sex is a risk factor for the mental health quality of life in Chinese COVID-19 patients [25]. In a study in which the SF-36 scale was applied, it was shown that Physical Function and Pain in women in Diabetic Foot Disease had worse outcomes [28]. A possible explanation for these results may be the lack of adequate sample size.

In many studies, cough and dyspnea was reported as persistent symptoms after COVID-19 infection [24, 29-32]. Our study found that; cough, dyspnea and chest pain was found to be agrevated after two months follow up. In first and second admission to our COVID-19 Follow-up Centre, cough is the cardinal symptom that persists. This study confirms that cough is associated with not only common in patients admitted to intermediate care/intensive care units [33]but also the most continuing sypmtom after COVID-19 [34].

A Chinese study, compared pulmonary rehabilitation and control group for quality of life after six weeks in post COVID-19 elderly patients and no change was reported in any subgroup of SF-36 in control group . The methodology of that study is different from ours, however it shows similarity with our study as it is also a follow-up study on quality of life. Different from the above study, in our study quality of life was negatively affected after two months follow-up. Ethnic, age differences and also longer follow-up time than Chinese study may explain these different results.

Prior studies that have noted the importance implacations of gender and age on quality of life was enlightened [35-39]. In a study conducted in China with post COVID-19 patients were evaluated in terms of SF-36 values change at 3 months after disharge from hospital and the values were reported to be lower when compared with Chinese people normal values of SF-36 [40]. Besides in female patients, most of the SF-36 subgroups were reported lower scores than male. Further analysis showed in this study showed that elderly patients were found to have lower general health and physical function scores than adult patients [40]. In another Chinese study investigating association between age and gender with quality of Life, Chen (2020) reported that, most of subgroups were found to be lower from general Chinese population and physical function and physical role was reported to be negatively associated with age, also physical function and emotional role were reported to be negatively associated with female gender when post COVID-19 patients were interviewed with SF-36 after 1 month discharge [25]. Cross- 
sectional studies such as these do not necessarily show subtle changes over time. This cohort study seeks to obtain data gives 6-month follow up which will help to address these research gaps in the post COVID-19 period. We also evaluated SF-36 change according to gender, age and treatment places. At the first admission, the ongoing treatment and rehabilitation process of the patients were recorded. When the patients came for the second control, those who found worsening in their complaints and general health evaluation were referred to the relevant units (Chest Diseases, Cardiology, Psychiatry, Physical Therapy and Rehabilitation, etc.). Being able to detect and document this situation has set an example for the multidisciplinary approach of the COVID-19 follow-up center, and it has been concluded that the spread of such centers will enable the detection of patients and their follow-up with a holistic approach.

The scope of this study was limited in terms of the lack of sample size that study was conducted as a retrospective single design. The results of this research support the idea of almost 1 year following up COVID-19 patients in single COVID-19 Follow-up Centre. Since the study was limited to 6 months followup after diagnosed with COVID-19, it was not possible to fully understand the effects of long term COVID19. On the other hand, we believe the present study lays the groundwork for future research into the long term effects of COVID-19 and further studies regarding the role of COVID-19 Follow-up Centres all around the world.

\section{Conclusions}

The purpose of the study was to determine quality of life with SF-36 and identifying parameters that change by time of admission to COVID-19 Follow-up Centre. This study has also identified, there is a growing necessity of evaluation long term COVID-19 patients in a better understanding of disease needs to be developed. Further studies regarding the role of COVID-19 Follow-up Centres would be worthwhile in terms of thoroughly examination.

\section{Declarations}

\section{Acknowledgment}

Authors of the study would like to express their gratitude to all doctors, nurses, and personnel who have been involved in the fight against COVID-19.

\section{Authors' contributions}

$\mathrm{AU}$ and FB contributed to the study conception and design. YB participated in the sequence alignment and drafted the manuscript. FŞM participated in the design of the study, performed the statistical analysis and helped to revise the manuscript. All authors commented on the latest version of the manuscript, and all authors read and approved the final manuscript.

\section{Funding}


The authors declare they have no financial interests. No funding was received for this study.

\section{Availability of data and materials}

Available upon reasonable request from the corresponding author.

\section{Ethical approval}

The study was approved by the Turkish Ministry of Health and the Ethics Committee of the Faculty of Medicine at Eskişehir Osmangazi University (date: 21.09.2021 decision number: 04)

\section{Consent for publication}

Not applicable.

Competing interests

All of authors declare that there is no conflict of interest in this study.

\section{References}

1. WHO Coronavirus (COVID-19) Dashboard I WHO Coronavirus (COVID-19) Dashboard With Vaccination Data. https://covid19.who.int/. Accessed 22 Apr 2021

2. Yelin D, Wirtheim E, Vetter P, et al (2020) Long-term consequences of COVID-19: research needs. Lancet Infect Dis 20:1115-1117

3. Wang C, Pan R, Wan X, Tan Y, Xu L, Ho CS, Ho RC (2020) Immediate psychological responses and associated factors during the initial stage of the 2019 coronavirus disease (COVID-19) epidemic among the general population in China. Int J Environ Res Public Health. https://doi.org/10.3390/ijerph17051729

4. LG J, E GP, D L-DB, et al (2020) Persistence of symptoms and quality of life at 35 days after hospitalization for COVID-19 infection. PLoS One. https://doi.org/10.1371/JOURNAL.PONE.0243882

5. Xu K, Cai H, Shen Y, et al (2020) Management of COVID-19: the Zhejiang experience. Zhejiang Da Xue Xue Bao Yi Xue Ban 49:147-157

6. Karimi M, Brazier J (2016) Health, Health-Related Quality of Life, and Quality of Life: What is the Difference? Pharmacoeconomics 34:645-649

7. Dowdy DW, Eid MP, Dennison CR, Mendez-Tellez PA, Herridge MS, Guallar E, Pronovost PJ, Needham DM (2006) Quality of life after acute respiratory distress syndrome: A meta-analysis. Intensive Care Med 32:1115-1124

8. Angus DC, Carlet J (2003) Surviving intensive care: A report from the 2002 Brussels Roundtable. Intensive Care Med 29:368-377 
9. Batawi S, Tarazan N, Al-Raddadi R, Al Qasim E, Sindi A, Al Johni S, Al-Hameed FM, Arabi YM, Uyeki TM, Alraddadi BM (2019) Quality of life reported by survivors after hospitalization for Middle East respiratory syndrome (MERS). Health Qual Life Outcomes. https://doi.org/10.1186/s12955-0191165-2

10. Ngai JC, Ko FW, Ng SS, To KW, Tong M, Hui DS (2010) The long-term impact of severe acute respiratory syndrome on pulmonary function, exercise capacity and health status. Respirology 15:543-550

11. Liu K, Zhang W, Yang Y, Zhang J, Li Y, Chen Y (2020) Respiratory rehabilitation in elderly patients with COVID-19: A randomized controlled study. Complement Ther Clin Pract 39:101166

12. Valent A, Dudoignon E, Ressaire Q, Dépret F, Plaud B (2020) Three-month quality of life in survivors of ARDS due to COVID-19: A preliminary report from a French academic centre. Anaesthesia, Crit Care Pain Med 39:740

13. Heyland DK, Hopman W, Coo H, Tranmer J, McColl MA (2000) Long-term health-related quality of life in survivors of sepsis. Short Form 36: A valid and reliable measure of health-related quality of life. Crit Care Med 28:3599-3605

14. JE W (2000) SF-36 health survey update. Spine (Phila Pa 1976) 25:3130-3139

15. Cortinovis M, Perico N, Remuzzi G (2021) Long-term follow-up of recovered patients with COVID-19. Lancet 397:173-175

16. Nalbandian A, Sehgal K, Gupta A, et al (2021) Post-acute COVID-19 syndrome. Nat Med 2021274 27:601-615

17. Kamal M, Omirah MA, Hussein A, Saeed H (2021) Assessment and characterisation of post-COVID19 manifestations. Int J Clin Pract 75:e13746

18. COVID-19 (SARS-CoV-2 INFECTION) GUIDE REPUBLIC OF TURKEY MINISTRY OF HEALTH DIRECTORATE GENERAL OF PUBLIC HEALTH.

19. FO F, F van N, I W, D T, D C (2018) Measurement properties of the Short Form-36 (SF-36) and the Functional Assessment of Cancer Therapy - Anemia (FACT-An) in patients with anemia associated with chronic kidney disease. Health Qual Life Outcomes. https://doi.org/10.1186/S12955-018-09338

20. R P, AM M-L, L F, GM C, B F, G C, L G, R C (2006) The quality of life in patients with chronic pancreatitis evaluated using the SF-12 questionnaire: a comparative study with the SF-36 questionnaire. Dig Liver Dis 38:109-115

21. RO H, LK W, D C, RB P, KJ C, JF O (2005) Two-year cognitive, emotional, and quality-of-life outcomes in acute respiratory distress syndrome. Am J Respir Crit Care Med 171:340-347

22. MS H, AM C, CM T, et al (2003) One-year outcomes in survivors of the acute respiratory distress syndrome. N Engl J Med 348:683-693

23. PP P, TD G, JC J, et al (2013) Long-term cognitive impairment after critical illness. N Engl J Med 369:1306-1316 
24. Carfi A, Bernabei R, Landi F, Group for the GAC-19 P-ACS (2020) Persistent Symptoms in Patients After Acute COVID-19. JAMA 324:603-605

25. Chen K-Y, Li T, Gong F-H, Zhang J-S, Li X-K (2020) Predictors of Health-Related Quality of Life and Influencing Factors for COVID-19 Patients, a Follow-Up at One Month. Front Psychiatry 0:668

26. Wong AW, Shah AS, Johnston JC, Carlsten C, Ryerson CJ (2020) Patient-reported outcome measures after COVID-19: a prospective cohort study. Eur Respir J. https://doi.org/10.1183/13993003.032762020

27. Brugge S van der S- van der, Talman S, Winter LB- de, Mol M de, Hoefman E, Etten RW van, Backer IC De (2021) Pulmonary function and health-related quality of life after COVID-19 pneumonia. Respir Med 176:106272

28. Core MA Del, Ahn J, Wukich DK, Liu GT, Lalli T, VanPelt MD, Raspovic KM (2018) Gender Differences on SF-36 Patient-Reported Outcomes of Diabetic Foot Disease: https://doi.org/101177/1534734618774664 17:87-93

29. Seeßle J, Waterboer T, Hippchen T, Simon J, Kirchner M, Lim A, Müller B, Merle U (2021) Persistent symptoms in adult patients one year after COVID-19: a prospective cohort study. Clin Infect Dis. https://doi.org/10.1093/CID/CIAB611

30. Ladds E, Rushforth A, Wieringa S, Taylor S, Rayner C, Husain L, Greenhalgh T (2020) Persistent symptoms after Covid-19: qualitative study of 114 "long Covid” patients and draft quality principles for services. BMC Heal Serv Res 2020201 20:1-13

31. Stavem K, Ghanima W, Olsen MK, Gilboe HM, Einvik G (2021) Persistent symptoms 1.5-6 months after COVID-19 in non-hospitalised subjects: a population-based cohort study. Thorax 76:405-407

32. Goërtz YMJ, Herck M Van, Delbressine JM, et al (2020) Persistent symptoms 3 months after a SARSCoV-2 infection: the post-COVID-19 syndrome? ERJ Open Res 6:00542-02020

33. Korell F, Giannitsis E, Merle U, Kihm LP (2020) Analysis of Symptoms of COVID-19 Positive Patients and Potential Effects on Initial Assessment. Open Access Emerg Med 12:451

34. LG J, E GP, D L-DB, et al (2020) Persistence of symptoms and quality of life at 35 days after hospitalization for COVID-19 infection. PLoS One. https://doi.org/10.1371/JOURNAL.PONE.0243882

35. Luethi N, Bailey M, Higgins A, Howe B, Peake S, Delaney A, Bellomo R (2020) Gender differences in mortality and quality of life after septic shock: A post-hoc analysis of the ARISE study. J Crit Care 55:177-183

36. Ko H, Park YH, Cho BL, Lim KC, Chang SJ, Yi YM, Noh EY, Ryu SI (2019) Gender differences in health status, quality of life, and community service needs of older adults living alone. Arch Gerontol Geriatr 83:239-245

37. Gerino E, Rollè L, Sechi C, Brustia P (2017) Loneliness, Resilience, Mental Health, and Quality of Life in Old Age: A Structural Equation Model. Front Psychol 0:2003

38. Puciato D, Borysiuk Z, Rozpara M (2017) Quality of life and physical activity in an older working-age population. Clin Interv Aging 12:1627 
39. Mercier C, Peladeau N, Tempier R (1998) Age, Gender and Quality of Life. Community Ment Heal J $199834534: 487-500$

40. Qu G, Zhen Q, Wang W, et al (2021) Health-related quality of life of COVID-19 patients after discharge: A multicenter follow-up study. 30:1742-1750 